Гюнай Назим гызы БАДАЛЗАДЕ, orcid.org/0000-0003-4422-4746 докторант по программе доктора философии Института образования Азербайджанской Республики (Баку, Азербайджан) gunay.badalzade@mail.ru

\title{
ПРОБЛЕМЫ ПРОФЕССИОНАЛЬНОГО И ТРУДОВОГО ОБРАЗОВАНИЯ ЛИЧНОСТЕЙ С СИНДРОМОМ ДАУНА В ПРАКТИКЕ ТЕОРИИ ОБУЧЕНИЯ И ВОСПИТАНИЯ ЛИЦ С ИНВАЛИДНОСТЬЮ
}

\begin{abstract}
В статье отмечается, что в Азербайджане существуют специальные иколь для лиц с ограниченными умственными возможностями, чтобы дети, относящиеся к данной категории, могли вести самостоятельную жизнь после обучения в школе. Проблема заключается в том, что эти школь не предоставляют профессиональную подготовку детям с синдромом Дауна, поэтому они не могут использовать то, что они изучали после школь, в какой-либо трудовой деятельности. В частности, не существует докарьерных программ, которые согласовывались бы с деятельностью, которой учащиеся хотели бы заниматься в будущем. Профессиональное образование - важнейшая сфера соичализаџии людей с синдромом Дауна и основное условие интеграции в общество. Успешная профессиональная самореализация людей с синдромом Дауна происходит за счет множества компонентов, включая содержание и качество профессионального образования и профессиональной подготовки с дошкольного возраста, качество образования и подготовки на разных уровнях общего образования. Автором статьи подчеркивается, что, к сожалению, в настоящее время в нашей стране очень мало опьта профессиональной подготовки и достижений относительно людей с синдромом Дауна. Этот опьт необходим, чтобы понять, какие наибольшие трудности испытывают люди с синдромом Дауна при трудоустройстве и последующей трудовой деятельности, выявить, что их определяет, и какие задачи необходимо решить для улучшения ситуачии. В то же время следует признать, что некоторые люди с синдромом Дауна не смогут получить профессиональное образование из-за серьезности отклонений в их развитии. Однако мы можем что-либо сделать с организацией их профессионального образования и труда в соответствии с их потенцииалом. При этом причинь иногда зависят от внешних факторов: отсутствия квотных рабочих мест; стереотипных предрассудков о неспособности людей с ограниченными возможностями выполнять качественную работу; отсутствия объективного спроса на ту или иную профессию в районе, городе, области и т. д. Наличие всех этих препятствий негативно сказывается на профессиональной реабилитации молодежи с синдромом Дауна. Анализ результатов современных специализированных научно-исследовательских и методических работ позволяет определить вероятные причины этих проблем.
\end{abstract}

Ключевые слова: люди с синдромом Дауна, профессиональное образование, люди с ограниченными интеллектуальными возможностями.

Гюнай Назім кизи БАДАЛЗАДЕ, orcid.org/0000-0003-4422-4746 докторант за програмою доктора філософії Інституту освіти Азербайджанської Республіки (Баку, Азербайджан) gunay.badalzade@mail.ru

\section{ПРОБЛЕМИ ПРОФЕСІЙНОЇ ТА ТРУДОВОЇ ОСВІТИ ОСОБИСТОСТЕЙ ІЗ СИНДРОМОМ ДАУНА У ПРАКТИЦІ ТЕОРІЇ ОСВІТИ Й ВИХОВАННЯ ОСІБ 3 ІНВАЛІДНІСТЮ}

У статті наголошується, щзо в Азербайджані існують спеціальні школи для осіб з обмеженими розумовими можливостями, щуоб діти, які відносяться до иүієї категорії, могли вести самостійне життя після навчання в школі. Проблема полягає в тому, щзо ці школи не пропонують професійну підготовку дітям із синдромом Дауна, тому вони не можуть використовувати те, що вони вивчали після школи, в будь-якій трудовій діяльності. Зокрема, не існує докар'єрних програм, які б узгоджувалися з діяльністю, якою учні хотіли б займатися в майбутньому. Професійна освіта - найважливіша сфера сочіалізаџї̈ людей із синдромом Дауна та основна умова інтеграиї в суспільство. Успішна професійна самореалізачія людей із синдромом Дауна відбувається за рахунок безлічі компонентів, включаючи зміст і якість професійної освіти і професійної підготовки з дошкільного віку, якість освіти і підготовки на різних рівнях загальної освіти. Автором статті підкреслюється, щьо, на жаль, натепер у намій краӥні дуже мало досвіду професійної підготовки і досягнень щзодо людей із синдромом Дауна. Цей досвід 
необхідний, щзоб зрозуміти, які найбільші труднощі відчувають люди із синдромом Дауна під час пращевлаштування й подальшої трудової діяльності, виявити, щьо їх визначає, і які завдання необхідно вирішити для поліпшення ситуачії. Водночас слід визнати, щзо деякі люди із синдромом Дауна не зможуть отримати професійну освіту через серйозність відхилень в їхньому розвитку. Однак ми можемо щзось зробити з організацією їхньої професійної освіти і праці відповідно до їхнього потенціалу. При ичьому причини не завжди вільні від таких зовнішніх факторів, як: відсутність квотних робочих місць; стереотипні забобони про нездатність людей з обмеженими можливостями виконувати якісну роботу; відсутність об'єктивного попиту на ту чи іншу професію в районі, місті, області і т. д. Наявність усіх ичих перешкод негативно позначається на професійній реабілітації молоді із синдромом Дауна. Аналіз результатів сучасних спечіалізованих науково-дослідних і методичних робіт дозволяє визначити ймовірні причини ичих проблем.

Ключові слова: люди із синдромом Дауна, професійна освіта, люди з обмеженими інтелектуальними можливостяли.

Gunay Nazım BADALZADE, orcid.org/0000-0003-4422-4746

Doctoral Student in the Doctor of Philosophy Program Azerbaijan Republic Educational Institute (Baku, Azerbaijan) gunay.badalzade@mail.ru

\section{PROBLEM OF PROFESSIONAL AND LABOR EDUCATION OF PEOPLE WITH DOWN SYNDROME IN THE PRACTICE OF THE THEORY OF EDUCATION AND TRAINING OF PEOPLE WITH DISABILITIES}

In Azerbaijan, special schools for individuals with intellectual disabilities are established primarily to provide functional academics and vocational skills to this category of children to make them live independent lives after schooling. The concern is that these schools do not provide vocational training to children with intellectual disabilities, so they are not able to use what they learn after school in any work activities. In particular, there are no pre-career programs to link students to the activities they want to pursue in the future. Vocational education is the most important area of socialization of people with disabilities and Down syndrome and is a key condition for integration into society. Successful professional self-realization of people with Down Syndrome and disabilities deals with many components, including the content and quality of vocational education and training from preschool age, the quality of education and training at different levels of general education. Unfortunately, there are currently very few experiences in our country about the vocational training and achievements of people with intellectual disabilities, as well as people with Down Syndrome. These experiences are essential to understand what tasks should be implemeted to improve the situation.

At the same time, it must be accepted that some people with Down syndrome will not be able to receive vocational training due to the severity of their developmental disability. However, we can do something about the organization of vocational education and labor in accordance with their potential. At the same time, the reasons are not always hidden from external factors: lack of quota work; stereotypical prejudices about the inability of people with disabilities to do work of high quality; lack of objective demand for a particular profession in a region, city, region, etc. The presence of all these barriers has a negative impact on the vocational rehabilitation of young people with Down syndrome. Analysis of the results of modern specialized research and methodological work allows to determine the probable causes of these problems.

Key words: people with Down syndrome, vocational education, people with intellectual disabilities

Постановка проблемы. В современный период одним из важнейших вопросов является овладение людей с ограниченными возможностями профессией и обеспечение их определенной работой. Одним из основных направлений специального образования детей с ограниченными возможностями является подготовка их к будущей общественной жизни. Эта возможность предоставляется детям с ограниченными возможностями через уроки профессионального и трудового обучения для овладения профессией. Трудовое обучение направлено на развитие общей и малой моторики, коррекцию и компенсацию умственного и физического развития, а также на профессиональную подготовку. Люди с ограни- ченными возможностями, а также люди с синдромом Дауна нуждаются в обучении практически на каждом этапе своей жизни, чтобы жить как самостоятельная, продуктивная личность и адаптироваться к обществу. В этом направлении главная цель - жить независимо от других, уметь обеспечить себя и интегрироваться в общество.

Включение деятельности, направленной на приобретение навыков самостоятельной жизни в образовательной среде для лиц с ограниченными возможностями, служит достижению этих целей. Анализ исследований показывает, что умения самостоятельной жизни делятся на четыре области умений: умения, необходимые для достижения успеха; умения адаптации; умения социаль- 
ного регулирования, умения, предшествующие профессии, и профессиональные. Овладение карьерными и профессиональными умениями в рамках навыков самостоятельной жизни имеет большое значение для формирования независимых и продуктивных людей, как в настоящей, так и в будущей жизни. Овладение работой и профессиональными навыками дает людям с ограниченными возможностями трудоустроиться, заработать деньги, научится сотрудничеству и развить социальные отношения. Это также повышает их уверенность в себе и заставляет чувствовать себя полезными для общества. Приобретение этих навыков также способствует осведомленности общественности о людях с синдромом Дауна.

Людей с синдромом Дауна следует обучить определенной работе/ профессии, пригодной для них, чтобы развить их уверенность в себе и уменьшить их зависимость от других. Профессиональное образование направлено на развитие общих знаний, умений и отношений, не связанных с профессией, независимо от того, какая профессия будет выбрана в будущем, и включает предпрофессиональные навыки. С другой стороны, профессиональное образование направлено на развитие знаний, умений и отношений, относящихся только к одной профессии.

Отличие трудовой подготовки учащихся с синдромом Дауна от их нормально развивающихся сверстников обусловлено необходимостью усиления коррекции девиантного развития и подготовки будущих выпускников к полноценному участию в трудовой жизни современного мира, современных условий экономического развития (Коробейников, 2017: 49-55).

Анализ исследований. Среди достижений современных исследований наше внимание привлекают как труды азербайджанских и русских ученых-педагогов, так и зарубежных авторов, таких как Е. Ворошилова (Ворошилова, 1017), И. Коробейников (Коробейников, 2017), Д. Бролин и Б. Шацма (Бролин, Шацман, 1999), Л. Кортеринг (Кортеринг, 2000) и др., в которых рассматриваются их взгляды на данную проблему.

Цель статьи - анализ проблем профессионального и трудового образования личностей с синдромом Дауна в практике теории обучения и воспитания лиц с инвалидностью.

Задачами трудового обучения учащихся с синдромом Дауна являются: сформировать интерес по отношению к работе и соответствующие личностные качества (чувство ответственности, самостоятельность, умение работать в команде); коррекция и компенсация недостатков умствен- ного и физического развития; профессиональное образование для обучения после профессионально-трудовой школы.

Эти задачи особенно важны для учащихся с синдромом Дауна, которые в силу своих интеллектуальных и психофизических особенностей принимают программу, адаптированную к сложности работы. Для них необходимо создать психолого-педагогические условия, обеспечивающие формирование эффективного профессионального образования. Это фактическая основа нашего исследования. У учащихся с синдромом Дауна ограниченный выбор профессии, и по причине возрастающих требований к подготовке специалистов эти профессии сложнее освоить. Помимо этого, имеются также проблемы с трудоустройством.

Основной целью профессиональной реабилитации людей с синдромом Дауна является изучение особенностей организации профессионального обучения детей с ограниченными интеллектуальными возможностями в средней школе по адаптированной образовательной программе. Эти особенности можно направить следующим образом:

- изучить психофизиологическую готовность учащихся с ограниченными интеллектуальными возможностями к овладению профессиональной деятельностью;

- изучить педагогические аспекты формирования профессионального образования учащихся с ограниченными интеллектуальными возможностями;

- проанализировать систему профессионально-трудового образования учащихся с ограниченными интеллектуальными возможностями в теории и практике реабилитационных учебных заведений;

- проанализировать методическое обеспечение воспитательной работы по работе умственно отсталых учащихся общеобразовательной школы;

- изучить особенности формирования профессиональных трудовых навыков у учащихся с нормальным и патологическим отставанием развития в процессе трудового обучения и др.

Это практическая деятельность учителя трудового обучения по созданию в общеобразовательной школе особых образовательных условий для учащихся с ограниченными интеллектуальными возможностями. При организации профессионального обучения учащихся с ограниченными интеллектуальными возможностями в средней школе учитель должен учитывать следующие особенности: учитывать общие закономерности психофизического развития и индивидуальные особенности учащихся с ограниченными интеллектуальными 
возможностями; регулярно и систематически в процессе обучения развивать у учащихся с ограниченными интеллектуальными возможностями специальные трудовые умения и навыки.

Для успешной организации профессионального образования людей с синдромом Дауна желательно учесть вышеизложенное, а также провести сравнительный анализ развитых стран и местного опыта в данной области.

Изложение основного материала. Сегодня люди с синдромом Дауна живут дольше и лучше, чем когда-либо, и готовы к интеграции в общество. Интеграция в общество проявляется во всех сфеpax жизни. Возможности получения образования возрастают от раннего воспитания до окончания средней школы. Исследования показывают, что люди с синдромом Дауна не перестают учиться в возрасте 10, 15 или даже 21 года и хорошо обучаются до зрелого возраста. Такой подход существенно влияет на образование и выбор профессии. В настоящее время большинство людей с синдромом Дауна оканчивают среднюю школу в возрасте 21 года в рамках составной части программы среднего образования. После окончания средней школы некоторые из них могут найти работу. А тем, кто этого не сумел, грозит грустный финал. Почему? Потому что люди с синдромом Дауна могут получать образование до 21 года, и тогда возможности получения образования для приобретения базовых знаний, профессиональных умений и повседневных жизненных навыков резко сокращаются.

Существует несколько способов развить и отточить базовые навыки тех, кто обладает способностью учиться, но еще не готов к работе, что часто является последним важным шагом в деятельности. Большинство людей, которые не могут найти работу, имеют ограниченные возможности для развития интересов, которые могут придать больше смысла и ценности их жизни. Время и деньги, которые мы вкладываем в людей с синдромом Дауна с 21 года, тратятся не зря. В то же время мы должны искать способы создания и расширения возможностей для членов общества в возрасте старше 21 года. Этот процесс сопровождается определенными трудностями как в Азербайджане, так и во многих странах мира.

В ходе нашего исследования мы обнаружили несколько очень интересных и обнадеживающих фактов. Во многих странах мира имеется много людей с синдромом Дауна, которые получили образование и овладели определенной профессией. Дополнительную информацию можно найти, изучив истории успеха людей с синдромом Дауна, таких как Кристофер Бурке, который снялся в сериале «Жизнь продолжается», и его коллеги Санта-Моники, а также Андреи Фридман, которая водит машину и учится в колледже. Есть много других неизвестных, но успешных людей с синдромом Дауна. Например, Джон Тейлор дольше всех работает продавцом у Сэма Гуди в Нануэте, Нью-Гоал. Гласкок три года работал в Лос-Анджелесе на двух работах: в аптеке днем, а вечером в ресторане. Верность своему делу, работоспособность, сделали его ценным сотрудником для обоих работодателей.

Исследования показывают, что люди с синдромом Дауна могут и добиваются успеха. Есть тысячи талантливых людей, таких как Джон, Кристофер и другие, но им нужны возможности, предоставляемые полностью финансируемым Законом о реабилитации, чтобы реализовать свой потенциал. Несмотря на то, что профессиональное образование является обязательным, в большинстве сообществ оно фактически ограничено. Помимо этого, существуют поддерживаемые программы трудоустройства, но они ограничены из-за отсутствия финансирования. Программам, предназначенным для помощи людям с синдромом Дауна, часто мешает хроническое недофинансирование. Другие варианты, которые могут лучше соответствовать потенциалу этих людей, не исследовались и не разрабатывались.

Еще один ключ к успеху молодых людей с синдромом Дауна - эффективность систем личной и социальной поддержки. Кроме того, неспособность родителей и заинтересованных сторон обеспечить им доступ к существующим программам может привести к разочарованию и даже депрессии. Программы профессионального образования и консультации могут помочь восполнить этот пробел, информируя заинтересованные стороны о программах, расходах, транспорте и вспомогательных услугах. Усовершенствование программ профессионального и образовательного характера имеет решающее значение для многих достижений в области медицинских исследований, проводимых по всей стране (Ворошилова, 2017: 30-36).

Профессиональное образование - важное средство интеграции людей с ограниченными возможностями, а также людей с синдромом Дауна. Например, разработка программ профессионального образования для обучения учащихся с ограниченными интеллектуальными возможностями в Соединенных Штатах выявила ряд программ и практик, связанных с успешным профессиональным обучением учащихся с синдромом Дауна. Эти практики включают: планирование и оценивание перехода, ориентированного на человека; учебную 
программу и обучение на основе общины; индивидуальную профессиональную программу; трудоустройство до окончания школы; участие семьи в образовании лиц с ограниченными интеллектуальными возможностями. По словам авторов, эта практика одинакова в Великобритании и других развитых странах Европы. Поэтому подготовка лиц с ограниченными интеллектуальными возможностями к общей самостоятельности и трудоспособности требует внимания к всесторонне дисциплинированным программам профессиональной подготовки и планированию послешкольного образования, которые играют важную роль в специальных школах. Следовательно, необходимо понимать текущее состояние профессионального обучения в общей учебной программе, которая описывает методы, которые будут использоваться в обучении детей с ограниченными интеллектуальными возможностями (включая детей с синдромом Дауна). Профессиональное образование, как отмечалось выше, является важным средством интеграции людей с ограниченными возможностями, особенно с ограниченными интеллектуальными возможностями, в общество. Самое главное: профессиональное образование, предлагаемое в специальных школах, должно дать учащимся навыки самостоятельной жизни в будущем. Было выявлено, что некоторые специальные школы предоставляют очень хорошую профессиональную подготовку для детей с ограниченными интеллектуальными возможностями. Однако оказывается, что программы обучения и уровни, предлагаемые этим людям, часто не обеспечивают их подходящей работой. Кроме того, многие учащиеся, похоже, не могут продемонстрировать после окончания учебы навыки, которым они научились. Поэтому в нашем исследовании мы попытались выяснить, входят ли профессиональные программы, предлагаемые в специальных школах, в параметры беспрепятственной работы учащихся. С этой целью, учитывая отсутствие исследований и опыта в данной сфере в нашей стране, мы уделили больше внимания опыту зарубежных стран. Следует отметить, что в нашем исследовании мы отдавали предпочтение программам для людей с ограниченными интеллектуальными возможностями, потому что люди с синдромом Дауна относятся к категории людей именно с умственными ограниченными возможностями. Рассмотрим несколько программ:

1. Модели профессионального/карьерного образования для лиц с особыми потребностями (Бролин, 1978: 22-23).

Существует особая потребность в моделях профессионального и карьерного образования, основанных на профессиональном образовании и переходе для людей с ограниченными интеллектуальными возможностями. Применение этих моделей в данном исследовании поможет людям с синдромом Дауна, с одной стороны, и людям с ограниченными возможностями, с другой стороны, полностью реализовать ожидания общеобразовательных целей. Эти модели требуют, чтобы учащиеся имели доступ ко всем соответствующим классам профессионального образования с измененным профессиональным содержанием и дополнительными услугами по мере необходимости. Это требование привело к постоянному выбору профессии - от общепрофессиональных классов до отдельных программ профессионального образования. Примерами этой модели являются модель развития карьеры в школе и переходного образования для молодых людей с ограниченными возможностями, модель карьеры для лиц с особыми потребностями штата Огайо и трехэтапная профессиональная модель для молодых людей с ограниченными возможностями.

Концепция профессионального образования появилась в мировой системе образования в 1970-х - начале 1980-х годов и стала национальной приоритетной и предпереходной программной моделью. Под влиянием движения за карьерный рост профессионалы начали использовать более долгосрочный и расширяющий возможности подход к учащимся с ограниченными возможностями и их подготовке ко взрослой жизни. Бролин определяет карьерное образование как «пожизненный процесс, который приводит к акценту на карьере во всех предметах, классах, включая рабочее образование, программы стажировки, воспитание, карьерные исследования и бесплатную работу в качестве члена семьи, гражданина и ищущего досуг (Бролин, 1978: 22-23).

Исследователи выделили семь основных целей профессионального образования, многие из которых стали основными условиями переходного движения: помочь людям в получении профессиональных знаний, карьерного роста и принятия решений; предоставить людям общую занятость и способность адаптироваться; продвижение и реализация партнерства частного сектора и государственной школьной системы; образовательный и функциональный интерфейс, позволяющий учащимся сделать лучший выбор; реформировать образование путем усиления понятия «карьера» в академических классах; быть значимой частью жизни человека; защищать свободу выбора путем уменьшения предрассудков и стереотипов. 
Некоторые из программ раннего профессионального образования, успешно используемых учащимися с ограниченными возможностями, включают: модель, основанную на образе жизни и компетентностях; школьную карьеру и модель переходного образования; экологическую инвентаризацию; экспериментальную модель; модель развития карьеры.

Каждая из этих моделей предоставляет удобный способ соответствующим образом сочетать академические и функциональные жизненные навыки. Поскольку этот способ развивается в течение 30-летнего периода, важно, чтобы учителя принимали во внимание подход к профессиональному образованию при разработке учебных программ для удовлетворения современных потребностей учащихся с ограниченными возможностями, связанных с продуктивной, конкурентоспособной работой и значимой профессиональной деятельностью. Мы также предоставляем информацию о других исследованиях в этой области. Одно из них - это Европейское Агентство по развитию образования лиц с особыми потребностями, котоpoe в 1996-1999 гг. начало изучать документы, литературу по приёму на работу учащихся с особыми потребностями. Это стало отправной точкой европейских исследований обязательного образования (среднее и профессиональное образование и центры обучения), направленного на будущее трудоустройство учащихся с особыми потребностями. За обзором литературы последовал анализ проекта перехода от учебы к работе в 16-ти различных европейских странах. В рамках этого проекта были изучены основные проблемы, с которыми сталкиваются молодые люди с особыми образовательными потребностями, их семьи и специалисты, с особым акцентом на факторы и препятствия, которые способствуют переходу от школы к работе. Среди основных проблем, выявленных в проекте, имели место следующие: содержание профессионального обучения недостаточно соответствует требованиям рынка труда; учащиеся с особыми образовательными потребностями исключаются; их образование не ориентировано на сложные профессии, требующие диплома. В рамках проекта также были изучены возможные способы решения этих проблем, такие как расширение сотрудничества между всеми заинтересованными сторонами, согласование учебных программ и гибкость в практике обучения. Предлагаемые решения также будут рассматриваться как часть текущего исследования, чтобы оценить, произошли ли какие-либо существенные изменения за последние девять лет.
Профессиональное образование в специальных центрах в основном осуществляется с помощью подходов к профессиональной реабилитации. Центры делают упор на образовательные учреждения, специально предназначенные для людей с ограниченными возможностями. Многие европейские страны осуществляют инклюзивное образование, но в некоторых странах, таких как Германия и Словакия, большинство людей с особыми образовательными потребностями и трудностями в обучении размещаются отдельно. Есть некоторые предположения, что эти учебные заведения являются альтернативой для учащихся, у которых нет возможности найти работу на открытом рынке труда или найти место в поддерживаемой программе профессионального обучения. Целью этих программ в основном является развитие профессиональных навыков.

С начала 2009 года государственные учреждения для людей с ограниченными интеллектуальными возможностями в Финляндии объединились с некоммерческими организациями, которые обеспечивают питанием учащихся с различными образовательными проблемами.

Анализ проекта компенсаиионного профессионального образования длялюдей с синдромом Дауна.

Программы компенсации обычно предназначены для устранения негативных последствий для учащихся с ограниченными возможностями, которые не преуспевают в основной среде. В некоторых случаях попытки решить проблемы с программами компенсации привели к размещению учащихся с особыми образовательными потребностями в приютах, где они не всегда имеют положительный результат. Однако при определенных условиях эти программы позволяют большинству учащихся получить аттестат о среднем образовании и трудовые навыки (Робертс, 1992: 371-397).

Учащиеся с особыми образовательными потребностями почти не имеют возможностей и доступа к профессиональному образованию и обучению и все еще находятся в «маргинальном» состоянии в результате того, что они не участвуют в системе базового образования и не являются частью школьного сообщества.

Настоящее исследование представляет собой теоретический обзор литературы, который объясняет концепцию профессионального обучения для людей с синдромом Дауна. В обзоре литературы обсуждается профессиональная подготовка людей с ограниченными возможностями, особенно людей с синдромом Дауна, и их устройство на работу, а также текущие процессы профессионального оценивания. Первоначально была при- 
нята «Модель карьерного/профессионального образования и переходного периода для лиц с особыми потребностями» для изучения потребностей людей с ограниченными возможностями для будущей независимой жизни. Как показывает литература, как людям с ограниченными возможностями здоровья, так и их коллегам, не являющимся инвалидами, необходимо приобретать профессиональные навыки для будущей работы.

Помимо этого, обсуждались программы перехода от школы к работе, основанные на модели профессионального и карьерного образования для лиц с особыми потребностями. Эти модели объяснили навыки и программы, необходимые для подготовки людей с синдромом Дауна к их будущей жизни. Большинство планов перехода для учащихся с ограниченными возможностями часто касаются профессионального образования и занятости. В литературе было выявлено, что оценивание карьеры и выбор в первую очередь рассматриваются как предпосылка для адаптации к работе и трудоустройству. Как потребность в профессиональном обучении, так и наличие человеческих и материальных ресурсов важны для эффективного обучения людей с синдромом Дауна. Проанализированная литература показывает, что существует множество программ профессионального обучения, которые предоставляют людям с ограни- ченными возможностями широкие возможности для обеспечения своей будущей жизни. Это ясно показано в литературе, где большинство исследований, проводимых в глобальном масштабе, имеют потенциал для самостоятельной жизни и занятости. Из анализа литературы также можно сделать вывод о важности развития услуг переходного периода в частных школах, особенно для учащихся с синдромом Дауна. Таких учеников нужно научить, как и где они будут жить после окончания школы.

Выводы. Таким образом, по результатам изучения всей литературы и проектов, которые мы рассмотрели в данной статье, можно сказать, что профессиональное образование важно и целесообразно для людей с синдромом Дауна. Сегодня предпринимаются серьезные шаги по построению инклюзивного общества в мире и в Азербайджане. Профессиональное образование для людей с синдромом Дауна также важно в работе по расширению инклюзивного образования и обеспечению равных прав для всех людей.

В результате было доказано, что при правильной организации пропедевтических и базовых ступеней профессионального образования лиц с синдромом Дауна можно адекватно определить их место, цель и содержание, спрогнозировать и оценить результаты на уровне основных задач.

\section{СПИСОК ИСПОЛЬЗОВАННЫХ ИСТОЧНИКОВ}

1. Баллард, Г. Карьера для обучающихся с ограниченными возможностями. Нью-Йорк : Институт модных технологий, 1995. 189 с.

2. Бролин, Д., Шацман, Б. Развитие карьеры на протяжении всей жизни. Нью-Йорк : Лонгман. 1999. С. $22-23$.

3. Браун Л., Бранстон М. Стратегия разработки хронологически соответствующего возрасту и функционального содержания обучения молодежи и подростков с тяжелыми формами инвалидности. Журнал специального образования. 1999. № 3. С. 81-90.

4. Ворошилова Е. Мировой опыт решения проблем профессиональной самореализации людей с инвалидностью. Дефектология. 2017. № 4. С. 30-36.

5. Коробейников И., Ворошилова Е. Профессиональная самореализация молодых людей с инвалидностью: проблемы и перспективы решения. Дефектология. 2017. № 6. С. 49-55.

6. Коч Л.. Оценивание и планирование в рамках Закона об инвалидах Америки: стратегии самозащиты потребителей и сотрудничества с работодателями. Журнал профессиональной реабилитации. 2000. № 2. С. 14, 103-108.

7. Кортеринг Л., Бразиэль П. Карьерные желания, выражаемые молодыми людьми с ограниченными возможностями. Журнал профессионального образования для лиц с особыми потребностями. 2000. № 1. С. $23-33$.

8. Робертс Р. Профессиональная оценка и планирование. Справочник по травмам головы: неотложная помощь при спасении. Нью-Йорк, 1992. С. 371-397.

9. Робсон К. Исследование реального мира. Лондон, 2003. С. 463-476.

10. Руш Ф., Уилсон П., Хьюз К. Взаимодействие людей с тяжелой умственной отсталостью и сотрудников без инвалидности в интегрированной рабочей среде. Поведенческая модификачия. Нью-Йорк, 1995. С. 59-77.

\section{REFERENCES}

1. Ballard, G. (1995). Karyera dla obucayushixsa s oqranicennimi vozmojnostami. [Career Placement for Learning Disabled Students] Nyu-York: Institut modnix texnoloqiyc. 189 s. [in English].

2. Brolin, D., Shasman B. (1999). Razvitiye karyeri na protajenii vsey jizni. [Lifelong career development]. Nyu-York: Lonqman. P. 22-23 [in English].

3. Braun, L., Branston, M. (1999). Strateqiya razrabotki xroniceski sootvetstvuyusheqo vozrastu i funksionalnoqo soderjaniya obuceniya molodeji i podrostkov s tajelimi formami invalidnosti. [A strategy for developing chronological age 
appropriate and functional curricular content for severely disabled adolescents and young adults]. Jurnal spesialnoqo obrazovaniya. № 3. P. 81-90. [in English].

4. Voroshilova, E. (2017). Mirovoy opit resheniya problem professionalnoy samorealizasii ludey s invalidnostyu [World experience in solving the problems of professional self-realization of people with disabilities]. Defektoloqiya. № 4. P. 30-36. [in Russian].

5. Korobeynikov, I., Voroshilova, E. (2017). Prifessionalnaya samorealizasiya molodix ludey c invalidnostyu: problem i perspektivi resheniya [Professional self-realization of young people with disabilities: problems and prospects for solutions]. Defektoloqiya. № 6. P. 49-55. [in Russian].

6. Koc, L. (2000). Oseniyaniye i planirovaniye v ramkax Zakona ob invalidax Ameriki: strateqii samozashiti potrebiteley $i$ sotrudnicestva s rabotadatelami. [Assessment and planning in the Americans with Disabilities Act era: Strategies for consumer self-advocacy and employer collaboration]. Jurnal professionalnoy reabilitasii. № 2. P.14, 103-108. [in English].

7. Kortelinq, L., Braziel, P. (2000) Karyerniye jelaniya, virajaemiye molodimi ludmi s oqranicennimi vozmojnostami [Look at the Expressed Career Ambitions of Youth with Disabilities]. Jurnal professionalnoqo obrazovaniya ludey s osobimi potrebnostami. № 1. P. 23, 24-33. [in English].

8. Roberts P. (1992). Professionalnaya osenka i planirovaniye. Spravocnik po travmam qolovi: neotlojnaya pomosh pri spasenii. [Vocational evaluation and planning, in: Handbook of Head Trauma: Acute Care to Recovery]. New-York. P. 371-397. [in English].

9. Robson K. (2003). Issledovaniye realnoqo mira. [Real world research]. London. P. 463-476. [in English].

10. Rush, F., Ulson P., Xyuz K. (1995) Vzaimodeystviye ludey s tajeloy umstvennoy otstalostyu i sotrudnikov bez invalidnosti v inteqirovannoy rabocey srede. Povedenceskaya modifikasiya. [Interaction of persons with severe mental retardation and their non-disabled co-workers in integrated work settings. Behaviour Modification]. New-York. P. 59-77 [in English]. 